\title{
Severe lower limb malformation associated with other deformities and death in infancy in two brothers
}

\author{
K. FRIED, M. D. GOLDBERG, G. MUNDEL, AND R. REIF \\ From the Department of Genetics, Paediatrics and Pathology, Asaf Harofe Hospital, Tel-Aviv University \\ Medical School, Zerifin, Israel
}

SUMMARY Two brothers with severe and rare lower limb malformations but normal upper limbs ar腒 described. Both brothers had glans hypospadias and they died in early infancy. In the first brother thie limb malformation was a severe deformity of the right foot which was split and of rockerbottom shape with oligosyndactyly. In the second brother the right limb below the knee was more severely deformed while only the toes were involved in the left limb. Details of the clinical and pathological findings are described. The most likely mode of inheritance of this rare syndrome is autosomal recessive or X-linked recessive with variable expressivity.

Minor malformations of the lower limbs such as polydactyly and syndactyly are relatively frequent. Severe malformation such as phocomelia or absence of foot are much less common. Malformation such as split foot or partial absence of foot and below knee longitudinal defects are rare. The finding of such malformations in brothers without any involvement of the upper limbs and with associated malformations prompts this report.

\section{Family report}

Both parents originated from Poona, India, and belonged to the Jewish community of Benei Israel, but were not known to be related. There were no known cases of multiple malformation or malformations of the limbs in the family. The mother had low intelligence (IQ 70), but was otherwise normal and had a normal karyotype. The firstborn child of the parents, a girl (Fig. 1), was born small for dates but was found to be of normal development at the

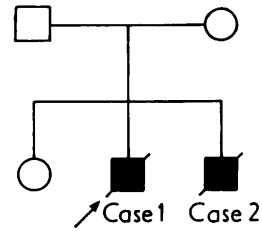

Fig. 1 Family pedigree. All members of the family were personally examined.

Received for publication 9 November 1976. age of 2 years. The second born was the propositus (case 1). He was born on 13 August 1975. The father and mother were 24 and 20 years of age, respectivel at the time of the proband's birth. Less than 10 montlys after the birth of case 1 , case 2 was born premature on 7 June 1976.

\section{Case 1}

\section{CLINICAL FINDINGS}

The propositus was born small for dates after an uneventful term pregnancy, during which the mother had no infections and the only drugs she received were iron pills in the sixth and seventh months of pregnancy, because of anaemia. The birthweight of the child was $2340 \mathrm{~g}$. He had a severe deformity of the right foot which was split and of rockerbottom shape, with oligosyndactyly (Fig. 2 and 3). He also had glans hypospadias and a sacral dimple. He w茨

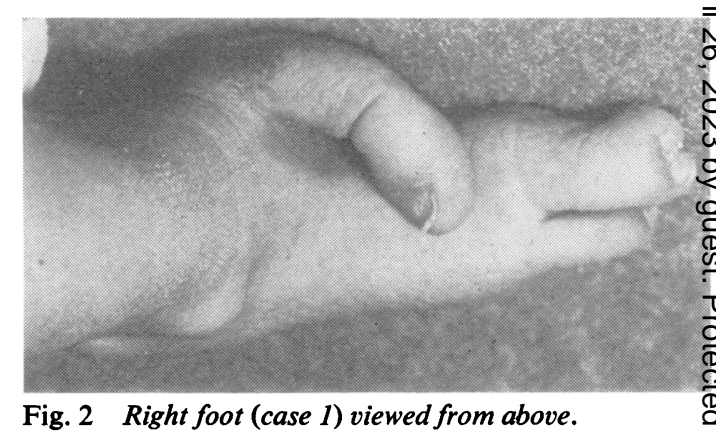




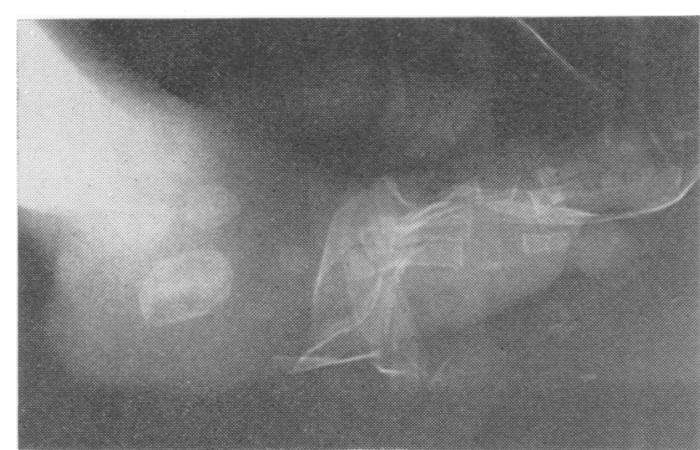

Fig. $3 \quad X$-ray film (case 1) of right foot showing split and rockerbottom foot with oligosyndactyly.

admitted to this hospital at the age of 2 months because of severe bilateral bronchopneumonia and he developed gastroenteritis and died at the age of $2 \frac{1}{2}$ months.

The karyotype was that of a normal male.

\section{PATHOLOGY}

The external examination showed a malformation of the right foot, with absence of the 2 nd toe and syndactyly of the 3rd and 4th toe and with a rockerbottom foot. The neck was short, the ears were relatively large and low set, and in addition a hypospadias was found. A minor internal malformation was present: a tendon-like fibre traversing the left cardiac ventricle from the septum to the posterior wall.

Histologically, evidence of sepsis was found, with bronchopneumonia with abscess formation, renal abscesses, and a septic spleen. The white matter of the large brain showed areas with sudanophilic material within astrocytes (following localised myelin destruction). There were no signs of a diffuse leucodystrophy.

\section{Case 2}

\section{CLINICAL FINDINGS}

This second affected son was born after the pregnancy was complicated by premature rupture of membranes at 22 weeks' gestation. During this pregnancy the mother did not have any infections and did not take any drugs. The child was born prematurely (after 7 months' gestation) with the cord around the neck 4 times. His birthweight was only $1270 \mathrm{~g}$ and the placenta weighed $350 \mathrm{~g}$. He had severe malformation of the right lower limb below the knee, with only minor malformation of the left toes(Fig. 4, 5, and 6). His upper limbs were normal. He was cyanotic and in severe respiratory distress. He also had glans hypospadias. The infant died on the second day of life.

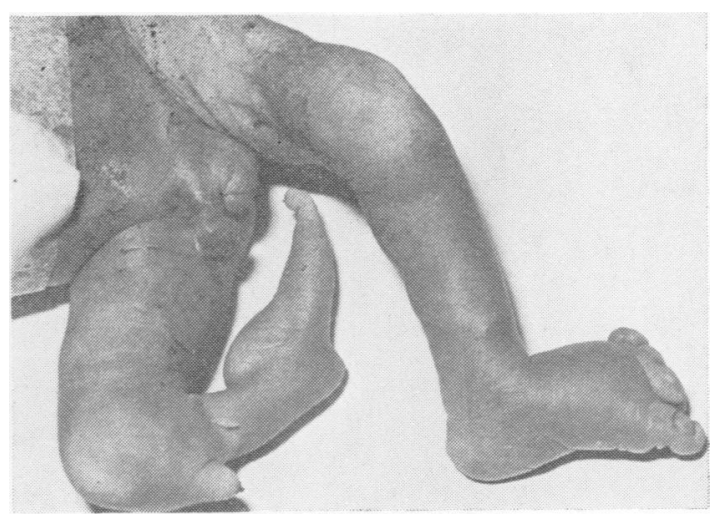

Fig. 4 Severe malformation of the right lower limb with only a malformation of toes in the left limb (case 2), better seen in Fig. 5.

The karyotype was that of a normal male.

\section{PATHOLOGY}

On external examination a malformation of the right leg was found with only partial development of the tibia (only of the proximal portion, about $3 \mathrm{~cm}$ in length). The fibula was normal and in continuity one set of phalanges of the foot was found to be developed normally. The left foot showed only minor toe malformation (Fig. 5); the upper limbs were normal. Hypospadias was present. Internal examination revealed an atrial septal defect, a bilateral ureteropelvic junction stenosis, and a slight septation of the spleen.

Histologically, diffuse pulmonary hyaline membranes were found, with recent intra-alveolar haemorrhages and atelectatic areas. An extensive extramedullary hematopoiesis was seen in different parenchymal organs. Examination of the tibia showed a gradual cone-shaped termination of the bone without any other apparent pathological findings.

\section{Discussion}

Emami-Ahari and Mahloudji (1974) have observed bilateral absence of the tibias, with deformities confined to the legs in 3 sibs, and suggested autosomal

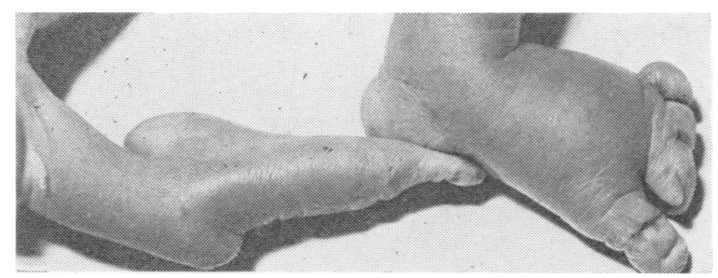

Fig. 5 Close-up of the feet (case 2). Note minute second toe attached to third toe on the left foot. 


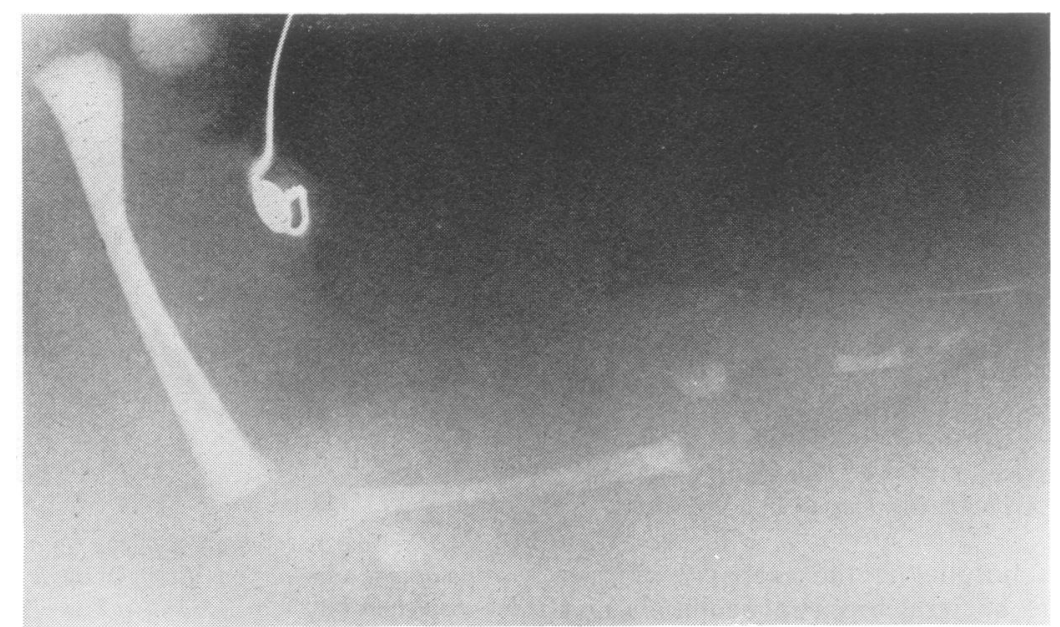

Fig. $6 X$-ray film (case 2) of the right lower limb showing gross malformation below the knee.

recessive inheritance. Mahloudji and Farpour (1974) described an unusual limb deformity in third cousins but in their cases the upper limbs were also involved. In both of the above reports the affected persons were adults or teenagers and there were no malformations described except those of the extremities. Freire-Maia (1970) described a syndrome of tetramelic deficiencies. In the present family, the limb malformation involved only the lower limb. In one brother (case 1), only the right foot was affected while in the other the right lower limb below the knee and the left toes were involved. They were both of low birthweight and had glans hypospadias and died in infancy. Case 2 had an atrial septal defect also. As they both died in early infancy, their mental status could not be evaluated. After the birth of case 1 and before the birth of case 2 , the parents were told that they run a risk of about $5 \%$ for a child with malformation. After the birth of case 2, the risk had to be re-evaluated, and the parents were told that the risk may be as high as $25 \%$ in view of the most likely recessive nature of the disease (whether autosomal or X linked).
The present family may have a 'new' syndrome with variable expressivity or it may be essentially a variation of the same disease as that described in the abovementioned family reports. The documentation of $\vec{\theta}$ further families with rare limb malformation is. needed.

\section{References}

Emami-Ahari,Z., and Mahloudji, M. (1974). Bilateral absence of the tibias in three sibs. In Limb Malformations. Birth Defects: Original Article Series 10, 5, pp. 197-200. The National Foundation-March of Dimes, New York.

Freire-Maia, N. (1970). The newly recognized genetic syndrome of tetramelic deficiencies, ectodermal dysplasia, deformed ears and other abnormalities. American Journal of $\bar{\nabla}$ Human Genetics, 22, 370-377.

Mahloudji, M., and Farpour, H. (1974). An unusual limb deformity in an inbred community. In Limb Malformations. Birth Defects: Original Article Series 10, 5, pp. 75-80. The National Foundation-March of Dimes, New York.

Requests for reprints to Dr Kalman Fried, Sackler School of Medicine, Asaf Harofe Hospital, Zerifin, Israel. 